\title{
Solvability for a nonlinear coupled system of Caputo fractional q-differential equations with nonlocal boundary conditions
}

\author{
Mohamed Houas ${ }^{1}$ and Muttalip Ozavsar ${ }^{2}$ \\ ${ }^{1}$ University of Khemis Miliana \\ ${ }^{2}$ Yildiz Technical University
}

July 26, 2020

\begin{abstract}
In this work, we study a nonlinear coupled system of fractional q-difference equations with nonlocal boundary conditions involving the fractional q-derivatives of the Caputo type. Uniqueness result for solution of the underlying problem is presented with the aid of Banach's contraction principle, while the existence result is derived from Leray-Schauder's alternative. Finally, we introduce some examples to support our main results.
\end{abstract}

\section{Hosted file}

mirro.pdf available at https://authorea.com/users/346194/articles/472306-solvability-fora-nonlinear-coupled-system-of-caputo-fractional-q-di\%EF\%AC\%80erential-equations-withnonlocal-boundary-conditions 